\title{
The Management Nexus of Imperfect Duty: Kantian Views of Virtuous Relations, Reasoned Discourse, and Due Diligence
}

\author{
Richard Robinson ${ }^{1}$
}

Received: 10 December 2016/Accepted: 10 August 2017/Published online: 22 August 2017

(C) The Author(s) 2017. This article is an open access publication

\begin{abstract}
A nexus of imperfect duty, defined as positive commitments that have practical limits, describes business behavior toward building affable and virtuous relations, maintaining reasoned social discourse, and performing the due diligence necessary for making knowledgeable business decisions. A theory of the development and extent of the limits of these imperfect managerial duties is presented here, a theory that in part explains the activities and personnel included under the firm's umbrella. As a result, the nexus of imperfect duty is shown to complement the perfect-duty-based nexus-of-contracts theory of the firm. The existence of flexible trade-offs involving these duties, trade-offs limited by contractual arrangements whether explicit or implicit, is shown to be one of the advantages of imperfect duty for developing business relations.
\end{abstract}

Keywords Kantian imperfect duties and their trade-offs . Moral judge and moral judgments · Due diligence · Theory of the firm

\section{Introduction}

Imperfect duty consists of those volitional commitments of moral value, but that have practical limits to their pursuit. That is the applicable definition utilized here. ${ }^{1}$ In Kantian terms, the practical limits to this duty are set by circumstances and inclination (see Kant 1797, 6: 452-454). This classification of duty is usually described and illustrated through terms of beneficent charity where the practical

Richard Robinson

robinson@fredonia.edu

1 School of Business, SUNY at Fredonia, Fredonia, NY, USA limit of circumstance requires that the giver not impoverish herself by the charitable action. The inclination limit is typically described as established by the giver's character, a personal attribute subject to development as in virtue ethics. ${ }^{2}$ For example, one might have an inclination toward one particular charitable action, but not another.

Imperfect duties, especially of the managerial sort, are much more extensive than those of the beneficent charity category; they include all of the imperfect commitments "to do good" involving relations both internal and external to the firm. To facilitate analysis of these relations, imperfect managerial duties are here classified into three overlapping broad categories: affable and virtuous relations, reasoned social discourse, and due diligence. Although imperfect duties have limited explorations in some previous business literature, broad notions beyond beneficent charity have not been explored. Ohreen and Petry (2012) explore the imperfect duty of business strictly in the context of corporate philanthropy. Mansell (2013) also explores this duty of beneficence in order to extend corporate moral obligations to wider stakeholder groups than shareholders, but does not venture into the categories explored here. Buchanan (1996) also explores the imperfect duties of business benevolence, but in the context of the collective action of moral suasion. Each of these efforts

\footnotetext{
1 The terms positive and negative duties, the former being identified with imperfect and the latter with perfect, are not utilized here due to the confusions this terminology generates, e.g., we have a positive duty to pay our taxes, but this could be interpreted as a negative duty to avoid being a tax cheat. The Kantian distinction of perfect and imperfect, as defined above, avoids this confusion; i.e., the former is absolute, the latter is open ended.

2 Annas (1993) emphasizes this development requirement of virtue ethics throughout her treatise.
} 
does not explicitly extend the use of the notion of imperfect duty beyond its use in charitable beneficence.

In addition to the perfect duties of management (duties referred to but not analyzed here), it is argued that these imperfect categories encompass all managerial duty. It is argued that they form a managerial nexus, i.e., a connected group that subsumes all related imperfect managerial duties, and that is based on the following broad managerial responsibilities:

1. The establishment, maintenance, and virtuous development of the management team,

2. The provision of reasoned communications with all stakeholders both internal and external to the firm,

3. The diligent performance of routine responsibilities, and perhaps diligent performance extensions beyond those routinely expected.

As utilized here, due diligence incorporates routine business functions such as capital budgeting, working capital management, logistical administration, internal control, marketing strategy, and the like. These all have imperfect duty components related to managerial performance due to resource and effort constraints and trade-offs as explored below (see The imperfect duty of due diligence section). Reasoned communications with all stakeholders is the heart of effective managerial communications, and as shown below, this overlaps with other due diligence components of management. Rationally explaining corporate policy enhances stakeholder relations and business effectiveness (see Boatright 2002). This component is also reviewed in detail. (See The Imperfect Duty of Reasoned Managerial Discourse section.)

Establishing a virtuous managerial team was recently explored by Robinson (2016). Such a pursuit establishes a structure of reinforcement of virtuous behavior characterized as imperfect duty. This is also extensively explored below. (See The imperfect duty of managerial affability and virtuous relations section.)

As a group, these three overlapping categories (managerial team building, reasoned discourse with all stakeholders, and due diligence in the other generally recognized business functions) are all encompassing, and as shown below, all have imperfect duty components worthy of exploration. For each of these three categories, the analysis presented here, however, poses ethical content in the form of both perfect and imperfect duty. The former duty fits the contractual model (both explicit and implicit contracts) that has extensive development since Coase (1937) (see Williamson and Winter 1993, for reviews of this "extensive development"). The latter imperfect duty is analyzed here as complementary to the perfect duty model. These three categories are therefore envisioned as including all of managerial duty and therefore as appropriate for facilitating analysis of the ethical content of managerial attitudes and actions. For example, it is shown below that managerial corporate charity and corporate social responsibility (CSR) are subsumed under due diligence with connections to virtuous relations.

As used in research, the usual purpose of categorization is to facilitate analysis. The three classifications are shown below to particularly facilitate examinations of (1) managerial character development, (2) the practical limitations to imperfect managerial duties, and (3) the trade-offs involved of one imperfect duty for another. These categorizations are therefore useful and justified.

\section{The Imperfect Duties of Management as Complements to Perfect Duties}

For purposes of proper distinction and analysis, this notion of a nexus of imperfect managerial duty should be juxtaposed with the well-established nexus-of-contracts theory of the firm since the former complements the latter. Alchian and Demsetz (1972), Jensen and Meckling (1976), and Fama (1980) described and developed this "nexus-ofcontracts" theory of the firm where each factor of production is an owner of a respective input. These efforts described ownership of the public corporation via a broader conception than merely the ownership of equity. This conception began with Coase's (1937) contribution that highlighted transactions costs, both internal and external to the organization, as related to explicit and implicit contracting as key to determining the extent and design of the business firm. This nexus approach explained the resulting impacts on ownership-management behavior:

Viewing the firm as a nexus of a set of contracting relationships among individuals also serves to make it clear that the personalization of the firm implied by asking questions such as "what should be the objective function of the firm," or "does the firm have a social responsibility" is seriously misleading. The firm is not an individual. It is a legal fiction which serves as a focus of a complex process in which the conflicting objectives of individuals (some of whom may "represent" other organizations) are brought into equilibrium within a framework of contractual relations. In this sense, the "behavior of the firm is like the behavior of a market; i.e. the outcome of a complex equilibrium process" (Jensen and Meckling 1976, p. 311).

If the purpose of viewing the firm, especially in its publicly traded corporate form, as a nexus of implicit and explicit contracts is to help with understanding the firm's design and behavior as a collection of individual commitments, then perhaps a complementary view of a nexus of 
imperfect managerial duties would supplement the contractual view to provide a more complete descriptivemodel of managerial behavior. Jeffrey Smith's (2012) and Norman Bowie's (1999) Kantian perspective is that firms are more than a nexus of contracts; they do have duties of beneficence within which corporate social responsibility (CSR) is grounded. Smith's and Bowie's observations concerning the CSR obligations of business, however, do not substantially generate a broader theory of the firm, nor a theory of managerial development, nor a fuller nexus-ofduty view, as provided here. The view of a nexus of managerial imperfect duties presented here, is one of business relations, but not specifically of ownership in its various forms.

One obvious difference in these views is that the nexusof-contracts model is largely one of positive observation, while the nexus of imperfect duty view presented here is one that largely poses norms, although there is observational support for the imperfect duty view as cited below. Another difference is that the notion of a contract, even of the implicit form, has a fulfillment boundary which, once reached, indicates discharge of the obligation. It is the nature of imperfect duties that they have no fulfillment boundary; they are open ended.

Contracts imply dichotomous behavior; i.e., either the contract is fulfilled or not, and once fulfilled, further activity of the sort specified halts, at least until a new contractual agreement is formed. There is no required further development in a contractual relation. Fulfilling a contract is, therefore, essentially a perfect duty. ${ }^{3}$ Williamson (1985) and Hart (1993), however, did explore "incomplete contracts" that result from the large transaction costs required for complete specifications of all contractual contingencies. For these latter contracts, perhaps imperfect duties of the sort explored here might play a role.

\section{The Imperfect Duties of Character Development}

Unlike with perfect duties, the imperfect duties of management are not generally dichotomous; they have no specific boundary of fulfillment and, as explained below, may develop over time with more favorable and advantageous managerial interactions. In this sense, managerial imperfect duties are not properly or best described as "contractual," but are rather better described as open-ended relations that continuously evolve,

\footnotetext{
3 Some contracts may be open ended, for which some degree of imperfect duty applies. For example, consider commodity futures (or forward contracts) where some range of grades of the good to be delivered is acceptable. The purchaser must rely on the supplier to not try and game-the-system by providing a poor grade, or by exploiting other manipulative methods for delivery (see Duffie 1989, Sect. 2.5, an Fackler 1993, for explorations of these manipulations).
}

relations of character, and its development. Perhaps these imperfect managerial duties could be described as open-ended implicit contracts, but this description is a bit convoluted in mixing perfect with imperfect duties, and it still begs the question, "What is the nature of these implicit duties?" This "nature" is the purpose of this exploration.

This nexus of imperfect duty view is shown to describe the behaviors of those business-involved individuals who "go beyond the expected effort," or who "fall short" of the expectations of some, but without any obvious consequences associated with falling short as might be implied by contractual relations. It is argued here that analyzing the managerial nexus of imperfect duties, i.e., those semiobligatory commitments with practical limits due to individual inclinations and circumstance, helps to explain (a) the behavior of individuals within the firm, (b) the relations firms develop with external stakeholders, and (c) the evolving nature of various business relations. In this sense, this nexus of imperfect duty view supplements the contractual view of the firm to provide a more complete vision of business behavior.

The theory posed here emphasizes management's implicit imperfect commitments to be diligent and civil, i.e., to behave according to business-cultural standards. They are "implicit" commitments because they are generally expected of management. The imperfect nature of these commitments serves a purpose, one that is more fully explained below, but that can be suggested here as involving (1) the duties related to the pursuit of affable and virtuous business relations, (2) notions of appropriate business discourse, (3) the often observed purposely vague commitments found in business, and (4) the requirements of, and limits to, managerial due diligence in business efforts. If these semi-commitments were not imperfect, but always of a hard-contractual sort, then business relations would be forced to be more limited, and constantly examined for contractual violations and recompense. Entering into non-contractual relations that involve the flexibility of imperfect duty, with its associated practical limits, allows business relations to be more easily formed and to develop though time and effort. Furthermore, this development may be stronger in some firms as compared to others, and this may help explain the success of some, and demise of others. (See the XeroxApple example presented in the section Imperfect Duty and the Boundary of the Firm.) In this sense, this exploration is aimed at providing a substantive complementary contribution to the theory of the firm, one that links notions of virtue ethics with Kantian character development for explaining business behavior (see Kant 1797, 6: 445-449). 


\section{Development of the Argument}

The purpose of this effort is (1) to pose a much broader view of imperfect managerial duty than only beneficent charity, although beneficent charity must be a component, (2) to explain this broad conception as complementary to the perfect duty view of contractual relations, and (3) to categorize the nexus of managerial imperfect duties so as to facilitate understanding of their nature including their practical limits and trade-offs. These arguments are presented in the following five sections:

- The classical notions of perfect and imperfect duty are briefly reviewed. This is necessary to remind readers of the foundational concepts.

- A theory of the practical limits of managerial imperfect duty is presented as being based on three propositions: (1) mutual dependence, (2) applicable knowledge for imperfect duty, and (3) imperfect duty to acquire relevant knowledge.

- The managerial nexus of affable and virtuous relations, reasoned discourse, and due diligence is developed. The former draws upon Robinson (2016), and the latter two draws upon business applications of socially broad maxims suggested by O'Neill (1995) and Rawls (1951). These maxims are reinterpreted to apply to management.

- The trade-offs associated with imperfect managerial duty are explored as advantages of this view of the firm. The imperfect duty nexus also suggests the benefits of character development for both the individual business person and the organization. This view helps explain the extent of the firm's boundary of activities and personnel, as complementary to the contractual model. In addition, the important managerial virtue of the noble nature of addressing ethical concerns in the necessary business-social setting is explored.

- A summary conclusion of the advantages of the nexus of imperfect duty model, as supplement to the perfect duty contractual model, argues that this complementary view is particularly insightful concerning managerial behavior.

\section{Classic Philosophical Notions of Duty}

Immanuel Kant (1785: 402-403) posed a process for deriving the moral maxims necessary for practical living, i.e., the categorical imperative process (CI process). He claimed that his categorical imperative merely reflects common reasoning concerning moral principles, a reasoning captured by three formulae, each consistent with and necessitated by the other two: (1) the formula of autonomy or universal law, (2) the formula for the respect for the dignity of others, (3) the formula of legislation for a moral community (Sullivan's 1994, p. 29, interpretations from the original German are used here).

Kant's second formula is generally interpreted as "Act so that you treat humanity, whether in your own person or in any other, always as an end and never as a means only" (Kant 1785, p. 429). This prescription can be interpreted as motivating a set of maxims we usually classify as duties although the interrelatedness of the three formulae implies that duty can be derived from each of the three. ${ }^{4}$ O'Neil (1995, pp. 114-115) terms the second formula "the formula on the ends-in-itself," and emphasizes its use as the foundation for perfect and imperfect duty. This vision of duty is particularly applicable to business which requires a set of moral rules (mostly prohibitions) to function. In particular, the second formula is generally interpreted as not only establishing prohibitions against the unethical actions of theft, fraud, coercion, and the like (perfect duties of prohibition), but also as requiring some degree of beneficent action (imperfect duty). Since the specification of this formula requires treating both oneself and others in serving each individual's personal ends, and not deceiving or coercing them into serving only one's own personal ends, imperfect duty naturally requires practical limits on beneficence, limits Kant founded in "circumstance and inclination" (see Kant 1797, 6: 454). Without such practical limits, one could impoverish oneself, or so exhaust oneself in pursuit of charity and the like, so that this duty would largely interfere with obligations to oneself. If broad obligations of beneficence were applied to business, but without practical limits, then business could hardly function in rationing and utilizing resources so as to provide goods and services to the general public.

The formula for legislating a moral community is generally interpreted as "All maxims that proceed from our own making of law ought to harmonize with a possible kingdom of ends" (Kant 1785, p. 436). This can be viewed as the motivational formula for establishing and pursuing duty since this "kingdom of ends" is generally interpreted as a "moral community." As reviewed by Korsgaard (1996, p. 23):

The human will must be seen as universally legislative. Each of us has a will that makes laws for itself as if for everyone. Since human beings together legislate the moral law, we form a moral community: a Kingdom of Ends. ... Each citizen takes his own perfection and the happiness of others as an end and treats every other as an end in itself. It is a

\footnotetext{
${ }^{4}$ For illustration purposes, Kant (1785) derived a set of five maxims from the formula of universal law.
} 
community engaged in the harmonious and cooperative pursuit of the $\operatorname{good}^{5}$ (Kant 1785, p. 432-433).

This can be used as an expression of an ideal vision for a business firm as community (see Robinson 2016, for this view of Kant's third formula).

In Kantian analysis, the pursuit of those duties that are consistent with the second formula should be motivated by a desire to pursue a moral community as specified in the third formula. This is particularly applicable to business where laws, regulations, enforceable contracts, and numerous internal-to-the-firm rules, as well as external ethical and professional codes, are common and serve this pursuit. This nexus of maxims exists to establish business as a myriad of moral agreements within an overall social/moral institution of markets.

For our business-organizational purposes, we can utilize Kant's explanation of his fundamental notion of applicable duty:

The duty of love for one's neighbor can, accordingly, also be expressed as the duty to make others' ends my own (provided only that these are not immoral). The duty of respect for my neighbor is contained in the maxim not to degrade any other to a mere means to my ends (not to demand that another throw himself away in order to slave for my end) $(1797,6: 450){ }^{6}$

\section{Perfect and Imperfect Duties for Business}

The analysis presented in this section distinguishes between perfect and imperfect duty. The following indicates the differences:

- Perfect duties are absolute prohibitions against attitudes and actions that violate a moral maxim of respecting the dignity of others. For example, there is an absolute prohibition against the lying promise, or fraud, or demonstrating contempt for the dignity of another.

- Imperfect duties are requirements for attitudes and associated actions that fulfill some moral maxim, but that have practical limitations. Charity, for example, must have practical limitations or the individual would not be capable of functioning in the everyday real world. This is a broad category, however, much broader than only charity. It includes beneficent duties for business agents as explored below. ${ }^{7}$

\footnotetext{
5 Also see Sullivan (1997, pp. 84-87) for a review similar to Korsgarrd's.

6 This is a Kantian passage that fully expresses the second formula's foundation for duty. For duty of virtue based upon respect, further see Kant (1797, 6:462).
}

Whereas perfect duty essentially requires non-interference with the freedom of others, imperfect duty requires beneficent attitudes and actions toward both others and ourselves, and hence has trade-offs and therefore practical limits. Perfect duties allow civilization to exist; imperfect duties allow the community, including the business community, to flourish. In Metaphysics of Morals (1797, 6: 394), Kant specified that perfect duties cannot be compromised by considerations of egoistic consequences.

Kant (1797) identifies imperfect duties as duties of virtue and describes these as of wide obligation and disposition (Ibid, 6:390). He also identifies an imperfect duty to oneself, as appears evident in the second formula of the CI, and describes this as a matter of character development.

Which of these natural perfections should take precedence, and in what proportion one against the other it may be a human being's duty to himself to make these natural perfections his end, are matters left for him to choose in accordance with his own rational perfection about what sort of life he would like to lead and whether he has the powers necessary for it (e.g., whether it should be a trade, commerce, or a learned profession).... a human being has a duty to himself to be a useful member of the world, ... But a human being's duty to himself regarding his natural perfection is only a wide and imperfect duty; for while it does contain a law for the maxim of actions, it determines nothing about the kind and extent of actions themselves but allows a latitude for free choice (Ibid, 6: 446).

The impetus of Kant's argument is that in each of the broad categories of imperfect duty, there is a maxim for action, but there is also latitude for discretion as to what the action might be, i.e., choose what contributions you will, but be of use to the world. Specific actions are not prescribed; some general broad categories of actions are prescribed, i.e., make the ends of others our own, but not to the point of personal exhaustion and degradation.

White (2011, pp. 41-46) suggests that imperfect duties are subject to preference rankings consistent with notions of taste. Still the rationality requirement of Kantian analysis, i.e., that moral decisions are made only after rational reflection, allowed Dworkin (1977) to describe a process for decisions involving imperfect duties: (1) gather all rational facts, (2) weigh these facts, and (3) then decide what is right through a balancing of obligatory judgment.

This process describes a type of cost-benefit analysis as decision criteria for imperfect duty and its logical foundation. Kant states that imperfect duties exist because we are ".... united by nature in one dwelling place so we can

\footnotetext{
7 In this context, beneficence means "doing or producing good."
} 
help each other" (Kant 1797, 6:453). This dwelling place applies to the business organization as well as other groupings of family and community. Kant terms this "the maxim of common interest" (Ibid, 4: 453). It applies to those united under the umbra of the business firm as "rational fellow-beings with needs" (Ibid).

Following Kant, Hill (2012, p. 86) lists several "midlevel" maxims from which a broader list of duties can be derived: perfect duties against lying or servility, and imperfect duties of charity, friendship, and promoting our own happiness. In Metaphysics of Morals (6: 379-413), Kant explored practical limits on all of these.

The duties of beneficence, friendship, and promotion of our own happiness all fall under the umbra of imperfect duty. Within the firm, however, an imperfect duty of beneficence, for example, must have a practical limit for individual managers and employees or they might not be able to function in their other business duties. Where should the line be drawn between what is practical, what is not, and what are the trade-offs of one dutiful performance with another? This question is not easily answered by the business person, but requires reflective thought, and is certainly unique to any situation at hand. A solution for discernment of these practical limits is posed in the next section.

\section{Imperfect Duty and its Practical Limitation}

According to Kant, the categorical imperative and its process reflects common thinking about morality and how our moral maxims are formed. In this sense, people might follow this process without explicit knowledge of philosophical deontology, Kantian or otherwise (see Kant 1785, "First Section," and Sullivan 1997, p. 29). Hence, management might follow what we classify as Kantian principles, either explicitly or at least implicitly, while recognizing that the self-worth of agents motivates them to "pursue their own morally permissible welfare and happiness, but also to promote those of others" (Sullivan 1994, p. 156). Following this view, we view markets and firms as expressions of the mutual dependence of their participants, who we assume aim at fulfilling their own needs, and those of others. Mutual respect, however, requires that these agents treat each other not merely as the means to their own ends, but must also allow others to pursue their ends, i.e., conditions specified under the second formula. This Kantian notion motivates the following proposition 1 , which is a version of Kant's maxim of common interest as reviewed above, but as it applies to business. ${ }^{8}$

\footnotetext{
${ }^{8}$ See Robinson (2016) for a similar statement. The only instance of "business interaction" that would violate this norm would be a tort or similar action to seek recompense for perceived previous offense.
}

1. Proposition of mutual dependence: Mutual respect requires that both sides of a business interaction not only pursue their own ends, but are also interested in enabling others to achieve their ends, i.e., "we make ourselves an end of others" and "through our will we make others our ends as well. The happiness of others is therefore an end that is also a duty" (Kant 1797, 6: 393).

Imperfect duties are necessary for promoting the interests of all, but in the analysis below, the closer the relationship between people, perhaps the greater should be their obligation of duty of an imperfect sort. If this imperfect obligation is stronger the closer people are, then this closeness is largely determined by the nature of the particular business or market interaction in question. This begs the interpretation of close upon which the practical limits to these actions of beneficence exist (see Kant 1797, 6: 454). This interpretation is examined below.

As reviewed above, both perfect and imperfect duties stem from our respect for the dignity of persons and are motivated by our pursuit of a moral community. This pursuit begs the question of which community do we refer to: family, business, some broad notion of stakeholders, or the entire business world? For any large business, managers are typically closer to their department or division than the overall business or the enveloping greater business community that includes broad notions of stakeholders. The more immediate the community, the greater the likelihood of actions aimed at the moral pursuit consistent with imperfect duties, and perhaps the more effective we would expect these actions to be. This is a reasonable claim because we expect that perhaps the more immediate the relation, the more the benefactor will likely know the most effective way to provide this duty at least to the extent they are ready to respond to the receiver's communicated desires.

We can hypothesize that our beneficent efforts would be more effective in smaller more immediate (or intimate) groups. This immediacy might heighten our knowledge of what those-to-be affected desire from our efforts and also what action would be the most effective. In a cost-benefit analysis, the cost of obtaining this information might be lower the greater the degree of intimacy or closeness. In fact, we could use the degree to which we have this knowledge to define our degree of closeness, i.e., those at greater physical distance could still be those whom we have the most information as-to-need and potential effectiveness of our efforts. Those closest-to-us by distance might still be those for whom we have little information about need or potential effectiveness. The interesting and relevant question then remains, "What do we mean by 
close in the context above?" This definition is highly relevant to what we mean by practical limitations to our imperfect duties. Hence the following proposition is posed:

2. Proposition of knowledge and imperfect duty: The greater the benefactor's degree of knowledge of the requirements of the intended receiver, the greater the obligation of imperfect duty between the benefactor and receiver, ceteris paribus. To the extent that closeness between agents generates knowledge concerning the needs of one or the other, the greater the obligation of imperfect duty of one-to-the-other without consideration of resource constraints.

One question that is begged by the propositions above concerns (1) whether the knowledge of the requirements of the intended receiver is passively obtained by the potential benefactors or (2) whether the knowledge developed by the benefactors is generated through their own efforts? The former surely exists in that we might passively obtain knowledge about the needs of others, but the latter poses an imperfect duty of virtue (character) to actively seek the knowledge relevant to a potential beneficiary. (This proposition is particularly relevant for managerial duty toward due diligence.) This poses a third proposition.

3. Proposition of imperfect duty to develop knowledge: We have an imperfect duty to develop knowledge about our potential obligations to others, and while this duty has practical limits, it is stronger among those who are closer.

Why should this duty be directly related to closeness? There are two possible reasons: (1) the closer the agents are, the easier the effort to obtain relevant knowledge of the needs of the other; (2) the closer the agents, the more likely it is for the action to be effective (as in actions among friends); hence, the cost of obtaining the knowledge is more likely to be borne. It is the very nature of friendly intimacy to assist one another from benevolent motives and also to express a degree of affability that also should be characterized as beneficence, i.e., "to do or facilitate good."

If we are to develop knowledge about the needs of others, and if we are to act on those needs, then virtuous relations are more likely to develop. If one person benefits by admiring the dutiful action of another, and therefore her commitment to imperfect duty is strengthened, then the dynamic of virtuous relations develops. This is the

\footnotetext{
${ }_{9}$ Note that Blum (1980) argues that imperfect duty is generated from the emotions of sympathy for the suffering of others. This is essentially Hume's (1739) but not Kant's argument.
}

Aristotelian process of virtuous relations referred to above, and it is founded on the three propositions presented above.

It follows from our analysis that since businesses are collections of agents of varying degrees of closeness, then duties of beneficence exist, and they are likely to be stronger within the firm, i.e., within its various internal stakeholders, than between the firm and external constituents, ceteris paribus. Applicable examples of these propositions are presented in the next section. These propositions also, however, imply limitations to imperfect duty due to limitations of knowledge, and these limitations are also explored in the next section. Virtuous character development may lead to greater knowledge via application of proposition 3 and as a result widen imperfect duty via application of proposition 2.

\section{The Managerial Nexus of Imperfect Duty}

The categories of imperfect duty, i.e., affable and virtuous relations, reasoned discourse, and due diligence, are described below as interrelated so as to form a nexus for management. In addition, it is argued that the imperfect duties associated with corporate social responsibility (CSR) are subsumed under due diligence, i.e., but it is also related to virtuous relations. The other duty elements of management are perfect and are associated with honesty and other juridical obligations. These broad and interrelated imperfect duties are examined in this section.

\section{The Imperfect Duty of Managerial Affability and Virtuous Relations}

Kant perceived friendship as the only relationship based upon our natural needs that also requires morality for its sustenance (see Kant 1797, 6: 471). Note that Aristotle's and Kant's views on friendship are notably similar on this point. ${ }^{10}$ This notion of friendship incorporates business relations both internal and external to an immediate establishment. Kant's three forms of friendship, (1) need, (2) taste, and (3) disposition (a disposition to recognize our neighbors as friends), all apply to these business relations. To be sustained, each of these categories

- Requires that we participate in the development and enjoyment of other's wellbeing through our morally good will,

- Arises from our general need to overcome our unsocial nature because of our survival need for social interaction, and

\footnotetext{
${ }^{10}$ See Cooper (1980) for a review of Aristotle's notions of friendships of virtue and of advantage.
} 
- Usually involves certain actions of reciprocity since friendship thrives on (but does not absolutely require) differences in capacities and personalities so that we naturally contribute to one another (Ibid, 6: 470-474).

To Kant, our "duty to oneself as well as to others is to not isolate oneself but to use one's moral perfection in social intercourse" (Ibid, 6: 472-473). This "social intercourse" particularly includes business, since perhaps besides family interactions, it represents our most frequent and socially important interaction. This imperfect duty of "non-isolation" is also an Aristotelian concept, but according to Kant, the "byproducts" of these friendly actions are "to create a beautiful illusion resembling virtue that is not deceptive" since all understand the nature of these actions ${ }^{11}$ (Ibid, 4:474). Here, Kant suggests that the illusion of the ideal is sufficient to be practical.

Affability, sociability, courtesy, hospitality, and gentleness (in disagreeing without quarreling) are, indeed, only tokens; yet they promote the feeling of virtue itself by a striving to bring this illusion as near as possible to the truth. By all of these, which are merely the manners one is obliged to show in social intercourse, one binds others too; and so they still promote a virtuous disposition by at least making virtue fashionable (Ibid, 4: 474).

By making these business virtues "fashionable," they literally should be considered as playing a role in generating what we consider as "business efficiency." These behaviors are the ideal style of business, a style that promotes commerce, a style of amicable and efficient norms both within the firm and for external dealings. This "fashion" is tangible and evolves due to what is most effective, but is rooted in effective sociability.

We should not view these fashions as deceptions since it is human nature to be at least somewhat social, and to adopt this "affability, courtesy, hospitality, and gentleness" for our social-business encounters as in other common encounters. (For insights into Kant's meaning of "social," see Ibid, 6: 472-473, and Kant 1784, 8:21.) They can be characteristics genuinely felt and adopted, and reinforced by business success. These characteristics, however, also have practical time and effort limitations. Hospitality, as an example, has its limit. Developing and enacting these characteristics are therefore imperfect duties.

Robinson (2016) points out the importance of virtuous relations in business. The benefits derived include the following:

\footnotetext{
$\overline{11}$ In business, these byproducts are not an illusion, but are definitely tangible.
}

- Relations of virtue stimulate a dynamic of reinforcement of ethical behavior, one individual reinforcing others. This is a basis of leadership. (This is an Aristotelian argument from Nicomachean Ethics, 1984, pp. 310-311.)

- Virtuous relations are sought among virtuous business managers and encourage longer-term relations within business firms.

- These longer-term relations lead to the firm-specific human capital investments necessary for business firm success.

This view empirically and theoretically rejects some previous arguments that virtuous relations were not found in business due to its competitive nature. Robinson (2016) argues that competition favors such relations.

The motive behind following the fashions of affability is relevant in Kantian analysis. If the motive is merely to succeed in business, then following this fashion is without moral content. If the motive is to pursue a moral community as in the third formula of the CI, i.e., a community that pursues the maxims consistent with the first two formulae of the $\mathrm{CI}$, then following these fashions is moral; it presumably serves moral ends. As indicated above, and also by Robinson (Ibid), affability opens the door to the dynamic of virtuous relations, the domain that generates broad imperfect duty. As indicated by Schneewind (1992) in addressing this Kantian issue, "The domain of virtue involves maxims that can be thought but not willed as universal laws. Most of what morality requires as action rather than abstention is a requirement of virtue" (Ibid, p. 323). In this, Schneewind is addressing the question of "Can we will actions from the maxims of imperfect duty?" The answer is that we cannot. We can will attitudes of respect for humanity from which both perfect and imperfect duties, including properly motivated fashions of affability, emerge. "To be virtuous, I must be acting for the sake of the good of another, or for my own perfection, and viewing these ends as morally required" (Ibid, p. 323). Specific actions are not dictated by these "maxims of imperfect duty," but in general, some action must emerge from these "attitudes of respect," but this depends on "circumstance and inclination" (Kant 1797, 6: 454).

Virtuous managerial relations are not just an instrument that serves pursuit of a moral community within business as some dutiful sacrifice. Humanity, whether acting within a business or externally to it, is social. As reviewed above, business people seek the friendships of virtuous relations because (1) we wish to enjoy the wellbeing of others and (2) we have a survival need for social interaction. Combining these needs with the other advantages reviewed above establishes our business-related theory of imperfect duty. 
The practical limit to the managerial imperfect duty of virtuous relations lies firstly in the proposition of mutual dependence. In managerial interactions, our duty is to enable others to pursue their moral ends while pursuing our own. This enabling, however, is limited by the extent of one's knowledge of the ends that these others seek, and the means others select to pursue these ends. The expected affability demonstrated between strangers in business is based on a lack of knowledge of each other, but these conventions of affability allow a gathering of knowledge that through time may develop into familiarity when the propositions of closeness and applicable knowledge may apply. The social conventions of affability, particularly as they apply to business, potentially lead to the imperfect duty to seek knowledge of the relevant needs of one another. The time and resource required to be affable, however, sets practical limits to these endeavors and also poses trade-offs in dealing with one person or another, or with other imperfect duties (see Schneewind 1992, for examination of the effects of "time and resource" constraints on duties of virtue).

\section{The Imperfect Duty of Reasoned Managerial Discourse}

Kant's CI process is capable of posing maxims of imperfect duty for guiding business discourse. The following five maxims and their practical limits were posed by O'Neill (1995, pp. 34-50) as broad principles for society (not specifically business), but they are particularly applicable to business management. The first four of O'Neill's maxims are clear specifications of imperfect duties. We explore here their applicability to the business nexus, and associated practical limits. The fifth of O'Neill's maxims specifies a prohibition against falsehoods, but there is an imperfect duty aspect to this that must also be explored. For example, management has an imperfect duty to try to be accurate in its business communications, although perfectly accurate might often be impossible. (Consider the accounting example of accurately measuring inventory under conditions of some degree of spoilage or obsolescence. One can estimate the inventory level, but some degree of inaccuracy must be accepted and communicated.)

(1) Managerial authority must be based on reason

Intolerance brings unreasoned authority to bear on communication. Wherever intolerance is practiced, whether by state or church or other bodies or individuals, those whose thinking and communicating are suppressed, are silenced not by reason, but by authorities that lack reasoned vindication. When these authorities govern us, the authority of reason is diminished, and our distance from a reasoned form of life and politics grows (O’Neill 1995, p. 48).

Managerial decisions should be based on properly communicated logical criteria that support the mission of the firm. These criteria are usually announced through well-articulated policy documents such as capital budgeting manuals, employee engagement manuals, corporate communication manuals, and the like. These written manuals attempt to articulate not only the necessary procedures, but the reasoned argument that supports these procedures. Reasoned clarity should promote understanding for the purpose of promoting adherence.

The practical limits to this imperfect duty are based first on the required clarity of the reasoned argument presented. Many constituents will choose to not accept the logic of the argument, however, finely presented, but always ask for more information, or simply deny the logical connections presented, no matter how clear they are. It is the psychology of accepting authority, no matter how logically based, that is the issue. The judgment of "how reasoned the argument is" should be based on the fictional "reasonable diligent judge," and not on the conception that "all must be persuaded." The imperfect duties of mutual dependence and applicable knowledge, both having practical limits, apply to the limits of this maxim. As a result, this maxim is an imperfect duty.

(2) Managers should tolerate the logical reason of others What does this imperfect duty imply? One who adopts it,

... detaches himself from the subjective personal conditions of his judgment, which cramp the minds of so many others, and reflects upon his own judgment from a universal standpoint (which he can only determine by shifting his ground to the standpoint of others) (Kant 1793, V, p. 294).

This prohibits indifference to the reasoned communication of others. The practical limit to this imperfect duty is that one cannot consider all arguments from every individual constituent, at least not without being too exhausted to perform other imperfect duties. Managers are not likely to have the time for all of these considerations, hence standardized policies are set, but managers should also be open to new evidence and new arguments that appear to be relevant and logical. Why? There are two reasons: (1) Managers should respect the dignity 
of those who try to communicate with them, and should even encourage these communications; (2) managers should consider evidence that is relevant to their firm's potential performance as posed by the three propositions presented above. The rationing of managerial time, however, poses practical limits.

(3) Reasoned argument should not be restricted or discouraged

Non-reasoned argument that denigrates, mocks, or bullies, or more generally fails to respect relevant constituents may make it difficult for others to articulate their logical argument, and hence, it violates the maxim to allow others to "think for themselves." These communications foment divisions between individuals and groups. The practical limits to this imperfect duty of "non-restriction" may pose the necessity for some form of censorship where its absence would lead to forms of defamation or harassment that lessens or stills the reasoned communications within the firm. This "do not restrict" maxim is consistent with Kant's universal principle of right. ${ }^{12}$ It is also an example of the acquisition of knowledge proposition, and its practical limit.

(4) Management should reason in common with those affected by its policy decisions

Management cannot expect to reason correctly unless it does so in common with those affected by its policies (see O'Neill 1995, p. 48). This "reasoning in common" requires broad social discourse within the firm, and also with various external stakeholders because it benefits the logical reasoning of management in that it makes it aware of the logical arguments of those so affected. This maxim provides an example of the mutual dependence and the acquisition of knowledge propositions and their potential limits. The practical limits to this imperfect duty consist of three sorts.

(a) To discover the reasoned arguments of affected stakeholders, management should prioritize the relevant groups. For example, when considering employee safety policies, management should certainly consult with workers from a production line. It is doubtful, however, that representatives of financial security holders should be consulted on this safety issue. With respect to capital budgeting procedures, or mergers and acquisitions,

\footnotetext{
12 Kant's universal principle of right (or justice) argues that the freedom of individuals should be maximized subject to non-interference with the freedom of others (see Kant 1797, 6: 231). This applies to freedom to try and persuade, an aspect of communication.
}

however, the reasoned arguments of financial security holders should be consulted, and perhaps the opinions of representatives of affected employees. It might also be important to consult some supplier stakeholders if they are directly affected, but not those unaffected.

(b) In many cases, those affected by managerial policies might be too numerous for individual consultations, but representatives might be expected to furnish the appropriate unbiased reasoned arguments related to their interests. These representative positions should be a sufficient substitute for numerous individual consultations and pose practical limits to mutual reasoned consultations.

(c) In the absence of relevant changes in circumstances, consultations with representative groups need not be repeated. The effort and time devoted can be costly, and this poses a practical limit to these consultations.

(5) Accuracy in managerial discourse should be pursued Falsehoods are clearly prohibited by all three formulae of the CI (see O'Neill 1995, p. 45, and Korsgaard 1986, pp. 325-349). Falsehoods in communication could not serve as a universal principle among a plurality of individuals. The practical limits, of course, concern situations of uncertainty, where management's declarations should be unbiased estimates of what it expects to be accurate, and that includes qualifying statements that indicate this uncertainty. There is an expectation of effort underlying the estimates of the relevant probability distributions, and this is subject to the due diligence of management. Due diligence efforts also have practical limits, and these limits are explored in greater detail in "The trade-offs" section.

\section{The Imperfect Duty of Due Diligence}

As explained in this section, the managerial obligations of due diligence are related to those required of affable relations. A personal inclination toward due diligence is a virtue, and these business relations of virtue might deteriorate without reinforcement from the due diligence efforts of others. These imperfect obligations consist of the following: (1) the knowledge requirement necessary for making properly informed decisions, (2) the requirement to apply the appropriate logically based decision rule, (3) the open-minded requirement especially in the face of stressful resistance, (4) the fair negotiations requirement, and (5) the "noble nature" requirement of speaking out in business discourse concerning ethical issues. The first three of these 
duties are examples of combinations of the propositions of mutual dependence, gathering of knowledge, and application of knowledge. The fourth and fifth, i.e., the "fairminded" and "noble nature" requirements, need more indepth exploration as provided below. The practical limits of each of the duties presented are also explored.

Rawls (1951) presents versions of the first four of these requirements in the context of the virtue characteristics required of moral judges versus the deontology requirements for moral judgements. Rawls, however, did not apply this to management. This application is presented and examined here.

(i) The knowledge requirement of due diligence Management should demonstrate a willingness to acquire the requisite knowledge concerning the consequences of its prospective decisions.

This is a restatement of proposition 3 , but in the specific context of due diligence. This requirement of willingness to acquire relevant factual knowledge, and also of the likely consequences of managerial actions, goes beyond the narrowly defined logic requirement presented below (requirement "ii"). The moral manager must never "shoot from the hip." This duty essentially requires a willingness to put forth the effort to acquire the necessary factual knowledge, but it also requires a willingness to analyze it. The efforts required for the acquisition of the relevant knowledge of the facts and to reflect upon those facts and also to reflect upon the consequences of potential various actions, even those actions that have no obvious ethical implication are themselves ethical obligations. They concern all business problems. Laziness in fulfilling one's business obligations certainly is unethical. ${ }^{13}$ Moreover, laziness in obtaining knowledge concerning a moral conundrum, or in reflection concerning the conundrum, is particularly unethical.

Acquisition of information is always costly in time, effort, and frequently financial resources. These costs pose the practical limits to this positive duty. In particular, time, plus the energy required of effort and financial resources are limited, and expending these on data acquisition involves opportunity costs.

(ii) The logic requirement $\mathrm{A}$ desire to use inductive logic is required of the business manager, as well as a desire to explore all options for decisions.

\footnotetext{
13 As an example of a managerial problem with perhaps no apparent ethical implication, consider the obligation for managers to economize on costs. This is an obligation managers have toward owners, and perhaps other stakeholders. This surely requires effort to explore options and to apply costs savings procedures. This is an ethical obligation of management.
}

This attribute is logically linked with "i." Logical explorations of decision options are required for modern business. How else can the consequences of managerial actions be explored? Furthermore, managers have a proactive obligation to not bring their prejudices or preconceived notions to their analyses. The pro-active obligation of managers is to logically explore options, to find new ones if possible, and to use imagination and creativity in this exploration. This is frequently the essence of the mental activities obliged for managerial decisions. Utilizing and listening to those who offer particularly creative analyses, perhaps from those below in the managerial hierarchy, follows from this requirement. This information must be considered and follows from the reasoning in common maxim explored in the section above.

As explored under the reasoning in common maxim, this imperfect duty for logic poses practical limits. Management cannot apply new logical analyses to the myriad of decisions they might face daily. Continually rethinking the logic of business decision making is overly daunting. For this reason, decision rules are usually expressed in standardized procedure manuals (capital budgeting manuals, human resource management manuals, and the like). This allows business to extend the practical limits in applying these rules. Explorations of all options, especially for "non-standard problems" that do not neatly fit the procedure manuals, also have limits in that managerial time and effort are finite.

(iii) The open-minded requirement The business manager must have a demonstrated willingness to reconsider judgments in light of new evidence. In addition, a knowledge of his or her own predilections, and a desire to consider all conflicting interests, is required. Ultimately, however, once management has reached the appropriate decision, it has the duty to implement it.

Ideology, prejudice and bias, should have no role in effective managerial decisions. Knowledge of self, and any biases one might have, is a necessary first step for overcoming those predilections. New evidence pertaining to managerial problems is frequently encountered, and we must utilize it in reexamination and possibly in reformation of our decisions. This attribute is really an extension of "ii" above.

Consideration of all conflicting stakeholder interests, however, does not automatically imply managerial discretion in balancing these interests. Knowledge of the conflicting interests of stakeholders may be required, but the manager represents the owners of the firm (and perhaps are owners themselves), and within this context, must fulfill all legal and contractual obligations to other stakeholders whether explicit or implicit. Ultimately, management's 
obligation is to implement logically correct properly supported decisions despite any psychological stress imposed by various constituents. Since management is generally compensated via some linkage to the firm's financial performance, it has an inherent conflict of interest in any attempt by it to impose their intuited ethical solutions to various stakeholder problems (as in management's imposition of subjectively balancing various interests). Because of these conflicts of interest, stakeholders would not likely accept any paternalistic management decree as being ethical. Consequently, management must negotiate fairly with various stakeholder groups. Hence, the criteria are listed as follows:

(iv) The fair-minded requirement The managerial decision maker is likely affected by the foreseeable consequences of the decision at hand. Since these conflicts of interest are often present in negotiations with various stakeholders, managers should make it clear that they are the legal agents of the owners (the essential conflict of interest), and should negotiate by objective rules of fairness as indicated below.

Fairness in negotiation requirements: Rather than authoritatively decreeing policies to various stakeholders, mangers should fairly negotiate these policies with stakeholder groups according to the criteria below.

(a) Given its legal-agency relation with owners, management should always present themselves to stakeholders as representing these owners.

(b) Subject to the conditions indicated below, management should not deceive, or coerce, or even impose strategic transactions costs aimed at biasing the negotiated results.

(c) In cases where critical information cannot be divulged in stakeholder negotiations, managers should attempt to bias negotiated results toward those reasonably expected if the information were known.

The idea behind the fair-minded requirement is to allow both parties to benefit from the negotiated outcome. The power potentially exercised by management should not be used to bias the negotiated results in a coercive way.

This fair-minded characteristic is generally assumed of moral managers, but it is difficult to realize since almost all decisions have some consequent effect on the manager involved. This attribute requires, however, that the manager has a disposition to try to recognize any inherent conflicts of interest, and to do all-that-is-possible to avoid them. For example, the manager of company $\mathrm{X}$ who signs contracts with company $\mathrm{Y}$, a company she also owns, cannot be said to be trying to avoid this conflict of interest.
Since almost all possible managerial decisions affect the financial condition of the firm, and via "ex post settlement" policies they then affect managerial compensation, managers are usually in violation of the "no conflict of interest requirement." ${ }^{14}$ Fair negotiations with non-owner stakeholders appear applicable, but finite managerial resources must limit these efforts to significant cases.

(v) The noble nature requirement The moral manager should be willing to exercise the Socratic noble nature of speaking out in a social context about the results of his or her reflective thought concerning ethical problems.

The other duties listed above may be of little value if the manager is unwilling to exhibit leadership in speaking to others in the organization about his or her analysis of ethical problems.

Conformity is a desire to not make waves within the organization. It is the opponent of the "noble nature" (see Arendt, 2003, p. 180). This noble attribute is necessary to resist the mob psychology that can sweep through organizations while attempting to justify even the most unethical actions. This noble attribute, however, is also necessary to prevent bureaucratic behavior where non-reflective application of "codes of conduct" is gamed to violate the spirit of the code but not the letter of the code. The logical rationale for the code must be emphasized. This "noble nature" subject is explored in more detail in the "virtue, character and noble nature" section.

\section{The Imperfect Duties of Corporate Social Responsibility (CSR)}

CSR largely requires perfect duties of conformance to society's demands. For example, most of our environmental standards for business are statutory, but some of these are complemented by the imperfect duties of due diligence. Consider the scientific investigations and knowledge required to understand business' impacts on the environment. These efforts are part of due diligence, and as expressed above, there are practical limits due to resource constraints. As such, there are trade-offs with other duties of due diligence.

Due diligence requires that, to some degree, management "thinks ahead" to attempt to envision its potential impacts on society through its product, production methods, human resource interactions, and other community interactions. This "envisioning" is the essential due

\footnotetext{
${ }^{14}$ Fama (1980) initiates the "ex post settlement" term and explains its meaning. It essentially involves managerial compensation as linked to firm performance. It should also be kept in mind that management is typically at least a part owner of the firm managed.
} 
diligence responsibility and is an imperfect duty in its broadest form. The human effort demanded must have practical limits, and trade-offs therefore must exist both within the envisioning tasks attempted, and managerial efforts toward other imperfect commitments.

CSR is also related to the imperfect duties of virtuous managerial relations, particularly virtuous community relations. To the extent that corporate behavior affects community interests, CSR is either a response that attempts to control negative externalities, or perhaps it is an attempt to generate positive externalities. These are attempts to either restore or establish virtuous relations. Hence, CSR is within both the domains of imperfect duty of due diligence and of developing virtuous relations.

\section{Benefits of the Imperfect Managerial Duty Model}

The benefits of the nexus of imperfect duty model of management, as complementary to the contractual model, stem from the insights the former has for the development of business relations and also for the trade-offs involved with these duties.

\section{The Trade-offs}

The above-listed imperfect duties of management (affable and virtuous, reasoned discourse, and due diligence) require practical limits posed by the finite resources of managerial time, effort, and finance. These practical limits for each category pose trade-offs. Four illustrative examples are presented here.

- The considerable requirements of due diligence in information gathering associated with any important business decision can limit the opportunity to reason in common with various constituents. Gathering data and presenting it to these same constituents for persuasive purposes can be part of the process of reasoning in common. This is a sort of "here is the relevant data, now we want comments from constituents" process. This process can be both time and effort consuming, with one reduced at the benefit of the other.

- Decisions involving larger businesses usually involve assertion of authority based on reason. Can all relevant constituents be heard from? At some point, the openminded duty must end in order to assert the reasoned authoritative decision.

- The requirement of civil and reasoned discourse attempts to allow all to be heard, but if this discourse begins to lead to a mob psychology with possible associated unethical conduct, then the noble nature of emphatically asserting that "this is wrong" may be warranted. On the other side, management cannot be continually asserting this noble nature in analysis of every possible declaration of inappropriate conduct, however weak the inappropriate conduct might be. There are limits that force trade-offs.

- Staying with established standard procedures to resolve typically encountered business decisions cannot allow those individual constituent members who are in opposition to be continually heard. There is an efficiency associated with standard procedures, an efficiency that is destroyed by interminable debate.

These trade-offs are subjectively established by an onthe-run management who need to pursue these duties, but who continually confront their practical limits. For this reason, these imperfect duties are not amenable to contracts, but supplement the contractual obligations of management. This issue is explored in more detail in the next section.

\section{Imperfect Duty and Contractual Obligations}

The apparent difference between the contractual model of the firm and the complementary imperfect duty view is that the former is largely based on positive observations, and the latter largely poses ethical norms. To some lesser extent, however, the latter also consists of positive observations of business' efforts toward imperfect duties (some of these are cited above as examples), and the contractual model is based on observed ethical norms where contracts are attempts to resolve moral conundrums. ${ }^{15}$ The impetus of the effort here, however, is to pose imperfect managerial duties as normative theory that complements the developed and observed contractual perfect duty model.

Trade-offs, such as those illustrated above, are not as apparent with the contractual conceptualization model of the firm since it is the dichotomous nature of contracts, they are either fulfilled or not. For this reason, it is difficult for business to contract the reasoned discourse behavior of management, or the open-minded behavior, or the noble nature behavior, since these behaviors have no clear expectations amenable to measurement, i.e., no clear boundaries of fulfillment. Contracts need specifications for behavior; hence, they are the natural domain of perfect duty and are not the natural domain of imperfect duty.

Business relations range from the hard-contractual relations at one extreme to the imperfect commitments at the other. In between, there are some open-ended contracts that mix the two: The contracts have fulfillment boundaries

\footnotetext{
15 Williamson (1985) presents extensive positive observations of the contractual institutions of business, but it also explains the role of these institutions in addressing the moral hazard problems of market interactions.
} 
plus some implied and open-ended imperfect duty responsibilities (see Hart 1993). The contractual obligation certainly has a central role in business, and exactly specifying a business contract, especially with associated collateral or recourse, is an attempt to reduce or eliminate the risk of non-fulfillment on both sides of the transaction. Developing interactions with implied imperfect duty, however, requires more of an assessment and reliance on the character of the business persons involved. The nebulous nature of the standards of performance for imperfect duties, i.e., the trade-off possibilities, poses an economic role as suggested above and explored below.

There are some duties of affable friendship, managerial discourse, and due diligence that manifest reasons for relying on character-generated imperfect duty rather than relying on the specification of contractual obligations whether implicit or explicit. The reasons for this reliance are:

- The transactions costs involved in forming contracts, with their tight specifications of obligations, can be high.

- Developing a character-exploratory relation in business comes in stages, with initial interactions reinforced and strengthened through latter interactions. Initiating the character-based responsibilities may have low immediate benefits and costs to both parties. These transaction costs are likely to be relatively low as compared to forming a contract when both sides have little initial information of the other.

- Character-generated relations have the potential for continual longer-term development once the moral character of those involved is assured. A simple contractual relation may have lower potential for revealing character (other than establishing that the contract is fulfilled or not). Information pertaining to the degree of duty pursuit, or avoidance, is not garnered through contracts, but this information is germane to decisions regarding further development of relations.

A character-generated relation requires judgment on both sides as to the moral worthiness of the other. These judgments pose reflections and evolving standards for both sides to meet. "Going beyond" is a continual challenge. Character and its evidence can initially develop, and from this initial development, additional business interactions can further develop. That is the advantage of these imperfect duty relations as compared to reliance on contracts. The latter poses a degree of personal distance, a distance not expected of character-generated relations. The friendship duties referred to above, i.e., the duties of affable-friendly discourse, as well as the duties of due diligence, are all manifested in character-generated relations. Without developing these managerial characteristics, business increases the probability of failure.

The internal-labor (human resource) market provides a good example of the advantages of the imperfect duty nexus. To a considerable extent, we can envision management as an arrangement of age-related cohorts: a spectrum of recent and young hires through long-time older and senior managers. There is no contractual (either explicit or implicit) commitment to any of these cohorts concerning advancement, but there is an understood imperfect duty-not an implicit contract-to fairly evaluate their potential for advancement. Furthermore, as indicated by Robinson (2016), the imperfect duties of civility and diligence, as reviewed above, promote the development of longer-term relations of virtue among the management team, upon which the long-term success of the firm likely depends. These relations develop through reinforcements related to the degree of demonstrated accomplishment of imperfect duty so that the character of the agents are manifested, discovered, and developed through time. ${ }^{16}$

\section{Imperfect Duty and the Boundary of the Firm}

Coase (1937) theorized that the transaction costs incurred from forming contractual combinations establish the extent of the firm. For example, consider a law firm deciding which areas of law to include within the boundary of the firm, and which to exclude. If some area is so frequently used that the transactions costs associated with retaining an outside attorney exceeds the salary of incorporating that legal expertise within the firm, then it is incorporated (subject of course to net benefit considerations). To do so, an implicit employment contract is formed with a legal expert in the area, although according to employment law there may be explicit contractual aspects. The actual person engaged, however, depends perhaps on the expectations with respect to the hire's commitment to imperfect duty.

There is validity to this contract theory, including the implicit-contract sort. It is based on observations of basic business-efficiency analysis. The extent of the firm, however, is also influenced by the firm's capability to develop the dynamic relations of virtue, where one virtuous individual reinforces and encourages the virtuous behavior of another (see Robinson 2016). Those firms which successfully establish a culture that incubates those dynamic relations should find it extends the boundary of its expertise for five interrelated reasons as pointed out by Choi and Storr (2016, p. 218):

\footnotetext{
${ }^{16}$ This process is consistent with the Aristotelian view of virtue ethics. See Annas (1993) for a full exploration of the virtue process of development.
} 
(1) Those who establish the trusting nature of relations of virtue will more easily lend themselves to cooperative interactions including those that lend expertise to the business problems of their counterparts. These trusting relations exhibit lower transactions costs than exhibited by implicit (or explicit) contracting. The economic-driven search for trustworthiness screens for reliable partners as an alternative to relying upon overly detailed and therefore more expensive contracts. This also lowers the monitoring associated with enforcing more detailed contracts. Here, "reliable partners" refers to those who commit to high degrees of imperfect duty through demonstrating trustworthiness.

(2) This trust also inspires greater flexibility than typically manifested by these contractual relations, a flexibility in managerial relations that leads to further economies generated from exploitations of mutually advantageous opportunities that appear possible due to the flexibility. Detailed contracts inhibit this flexibility. ${ }^{17}$

(3) This trust also inspires information sharing which implies further possible development of relations of advantage.

(4) This trust develops norms of fairness among the managerial team.

(5) Relations of virtue are desirable because when they occur within a business, they promote longer-term partnerships. Longer-term business relations build investment in firm-specific expertise of the sort that is beneficial to the efficiency of the firm.

Choi and Storr (Ibid) argue that "the market depends on and promotes trustworthiness as well as fairness and reciprocity." These advantages of "trust" were also pointed out in Robinson (2016) as benefits generated by developing virtuous relations. In addition, Wang et al. (2009) find that employees' investments in firm-specific expertise are enhanced by the "trust building devices" of the firm and that this firm-specific investment is essential to the success of the firm's strategy. ${ }^{18}$

As a result of the above points, the more effective the business is in creating relations of virtue, the greater the

\footnotetext{
$\overline{17}$ Consider bond indentures that restrict the potential activities of the issuing firm unless approved by a legal representative of the bond holders. These indentures inhibit the firm's flexibility to exploit new opportunities, and these indentures are often associated with the securities issued by less-credit-worthy firms. Highly rated firms do not generally face these indenture restrictions (see Smith and Warner 1979, Sect. 2, especially 2.1.6.)

18 The principle "trust building device" explored by Wang et al. (2009) was a grant of shares to employees. Robinson (2016), however, emphasizes the development of longer-term relations of virtue for trust building as in Aristotle's Nicomachean Ethics, 1984, pp. 310-311.
}

firm-specific knowledge developed, and the greater the cooperative nature of the management team in applying this knowledge. The boundary of the firm is therefore extended because the internal transactions costs are lowered through relations of virtue that result from performance of imperfect duty. This cooperation occurs through the imperfect duties of virtuous relations, reasoned discourse, and due diligence, which, because of the developed expertise, ultimately lowers the costs of solving business problems.

As one of many business-historical examples of this phenomenon, consider Apple's development of the mousegraphic interface (see Gladwell 2011). An early and primitive version of the mouse was first developed at Stanford Research Institute, but Gary Starkweather, an engineer at Xerox PARC who developed the highly successful laser printer for Xerox, developed it further as a tool for a graphic-user-interface. In 1979, Steve Jobs of Apple visited Xerox PARC and saw the mouse demonstrated. He set Apple engineers to work on quickly developing a simpler, more reliable, longer-lasting, and less expensive version. This was quickly accomplished and led to a significant success for Apple.

Engineer Starkweather indicated in an interview in 2011 that the problem at Xerox was one of communication and due diligence, not of creative invention (Ibid). The management bureaucracy at Xerox did not listen, or attempt to perceive the potential for the invented mousegraphic-interface, so Apple reaped its benefits. Whether an interference in communication between the management team and the company's innovative engineers, or a lack of due diligent performance in analyzing the business potential of the mouse system, or both, the Xerox management team's performance of imperfect duty broke down. This was not a violation of a contractual performance by Xerox's management (a violation of a perfect duty, even of the implicit contractual kind), but a nonperformance of an imperfect duty. The boundary for performance of imperfect duty for Steve Jobs and Apple's engineers, however, was much wider. The extent of this managerial boundary led to the success of one company, and the foundering of another.

Engineer Gary Starkweather was later hired by Steve Jobs to work for Apple. According to Starkweather, the reason for his change of company was that Xerox "constantly squashed" his ideas (Ibid). Relations of virtue as built upon standards of business discourse and due diligence, and which were perhaps once present at Xerox, had broken down. ${ }^{19}$ The extent of this company's boundary for

\footnotetext{
19 This breakdown has been blamed on the physical distance (3000 miles) between Xerox's corporate headquarters in Rochester, NY, and PARC's Palo Alto location (see "Xerox PARC," Wikipedia, 2016)
} 
imperfect duty narrowed to exclude, or at least limit, its research and development function, and the benefits of this function, and associated personnel, were transferred to Apple. This example illustrates the bullet point related to the linkage between the extent of the firm and imperfect duty as asserted in the Introduction.

\section{Virtue, Character, and the noble nature}

In The Metaphysics of Morals (6: 421-447), Kant especially emphasized duties of respect to oneself, i.e., duties to develop oneself physically, mentally, and also to develop one's character. Character is here defined as awareness of one's obligation toward others, and commitment to pursue these obligations, and in the social context perhaps leadership in this pursuit, or even appropriate followership. According to Kant, character is the essential virtue, and this requires attention and development. Combining this commitment with propositions 1, 2, and 3 yields a theory of the development of practical limits to imperfect duty. On a personal level, these practical limits depend upon the individual's developed character; in an organizational context, it depends upon the group dynamics and leadership within that group. The Xerox example reviewed above illustrates the breakdown of this development, in particular the breakdown of applying proposition 3, the proposition pertaining to the imperfect duty to develop relevant knowledge.

A theory of character-based imperfect duty for business therefore should contain three dimensions worth exploring: (1) leadership in this pursuit, (2) followership in this pursuit, and (3) and the group dynamics associated with this pursuit. Leadership requires what Hanna Arendt (2003, p. 180) terms "the noble nature," defined here as speaking out in a social context concerning what is "right or wrong." Arendt defines this personal virtue, in part, as $a$ love of justice, a personal virtue she ascribed to Plato. Arendt argues that "thinking is a marginal affair" in society, "except in emergencies." (Ibid, p. 188) With respect to these "emergencies," Arendt writes:

At these moments, thinking ceases to be a marginal affair in political matters. When everybody is swept away unthinkingly by what everybody else does and believes in, those who think are drawn out of hiding because their refusal to join in is conspicuous and thereby becomes a kind of action. The purging element in thinking, Socrates' midwifery, that brings out the implications of unexamined opinions and thereby destroys them-values, doctrines, theories, and even convictions-is political by implication. For this destruction has a liberating effect on another human faculty, the faculty of judgment, which one may call, with some justification, the most political of man's mental abilities (2003, p. 188-189).

Evil in an organizational setting is a violation of those rules that are based on rational thought. As a result, the counter to evil lies in this "noble nature," that is the desire to participate in rational thought in a social context. It is not, Arendt argues, the common reasoning person who is responsible for maintaining societal ethical conduct and therefore avoiding evil, but rather it is the person who exhibits the "noble nature" of reflective thought as voiced in the social setting who is necessary to avoid this evil. (This nature, given the above excerpt, appears to be better applied to Socrates than Plato.)

This "noble nature" requires rational and reflective commentary aimed at stimulating others to develop, explore, and clearly understand moral argument and obligations. This is a subject within the domain of managerial discourse. ${ }^{20}$ This means arguing against the mob psychology frequently found in us-versus-them movements that vilify some subgroup or competition, and that is found frequently in the authoritarian firm. For Kantian analysis of perfect duties, there is an obligation to at minimum attempt an argumentative interruption of any anti-duty group-think dynamic. The imperfect duty commitment is to go beyond this minimum in attempting to stimulate the opposite dynamic.

For imperfect duties such as those referred to above, management should also be inclined to analyze in a rational and reflective way the extent to which its duty should be extended, i.e., the acceptable limitations. This should be considered as individual character development, but this can also be applied to the overall business organization. The development of relations of virtue through focusing on leadership, followership, and group dynamics as suggested above can extend the institution's performance of imperfect duty. This occurs through the propositions presented above (propositions of mutual dependence, and of gathering and applying relevant knowledge). Practicing these propositions potentially extends the boundaries of the nexus under examination. Recognizing mutual dependence within a business, and gathering and applying relevant knowledge, all can widen the imperfect duty boundaries. The constraints and tradeoffs explained imply, in essence, an anticipated effectiveness boundary, i.e., we have an imperfect duty to extend these constraints through development of knowledge about the potential benefits.

\footnotetext{
20 This noble nature manifests a substantial portion of the essence of moral leadership, but only a "substantial portion" because other aspects of personal actions that quietly demonstrate moral commitment are not formally characterized as being part of the noble nature of social discourse.
} 
Without the relevant knowledge, the anticipated benefits are restricted, and boundary tightly constrained.

\section{Summary and Conclusion}

The three broad categories of imperfect managerial duties analyzed above, duties of affable and virtuous relations, reasoned discourse, and due diligence, form an all-encompassing nexus for business management. This categorization facilitates analysis of their managerial role, their practical limits, and their trade-offs. The above analysis demonstrates this.

This view of the nexus of norms of managerial imperfect duty complements the contractual-observational view of firm behavior, whether the latter is described by implicit or explicit contracts. Explicit contracts are essentially dichotomous, and implicit contracts are considerably so in that if either type of contract is unfulfilled, then recourse must be explored, and relations adjusted or perhaps ended. If the contracts are fulfilled, then there is no obvious and necessitated further development other than forming a new contract. Furthermore, forming contracts, even of the implicit sort, is likely to be somewhat of an expensive process in attempting to provide flexibility, and in its formation of specific requirements with potential recourse for violations. For this reason, the relations amenable to contracts are essentially those that demand little or no flexibility; they therefore reside in the domain of perfect duties. Many relations are, however, more amenable to imperfect commitments because of the need for flexibility, the difficulty of specification, and the desirability of continuous relational development, all of which can be facilitated by the exercise of imperfect duty as reviewed above.

The pursuit of imperfect duties within business allows the flexibility necessary to initially form and then develop following discovery and reinforcement of the virtuous character-based actions of those engaged. This view focuses on the degree of constraints on these imperfect duties associated with business. These constraints are explored above by a series of three propositions: (1) mutual dependence, (2) application of knowledge to imperfect duty obligations, and (3) imperfect duty to develop relevant knowledge. In the proper business development setting, these constraints potentially broaden to extend the limits of imperfect duty. This broadening describes individual character evolution within the successful firm and ultimately the institutional character evolution of the firm.

Furthermore, specifications of what is meant by managerial reasoned discourse, as based on O'Neill's (1995) suggested broadly social maxims, are presented above. They are used to explain the meaning of managerial reasoned discourse as imperfect duty. Similarly, the imperfect duty of due diligence is explained via application of Rawlsian (1951) requirements for judicial judgment and is here interpreted in the managerial context. This Rawlsian exploration specifies the knowledge, logic, open mindedness, fair mindedness, and noble nature requirements of due diligence in management as defined and described above.

Furthermore, the trade-offs involving these imperfect duties are explored above. In addition, the imperfect duty model is shown to contribute to the explanation of the firm's boundary of activities and personnel. Given all of these considerations, the imperfect duty model complements the contractual model of management. It adds insights and is applicable to explaining the development of business relations involving constraints and trade-offs.

\section{Compliance with Ethical Standards}

Ethical Approval This article does not contain the results of any studies with human participants or animals performed by any author.

Open Access This article is distributed under the terms of the Creative Commons Attribution 4.0 International License (http://crea tivecommons.org/licenses/by/4.0/), which permits unrestricted use, distribution, and reproduction in any medium, provided you give appropriate credit to the original author(s) and the source, provide a link to the Creative Commons license, and indicate if changes were made.

\section{References}

Alchian, A. A., \& Demsetz, H. (1972). Production, information costs, and economic organization. American Economic Review, 62, 777-795.

Annas, J. (1993). The morality of happiness. New York: Oxford University Press.

Arendt, H. (2003). Thinking and moral considerations. In J. Kohn (Ed.), Responsibility and judgment. New York: Schocken Books.

Aristotle. (1984). In J. Barnes (Ed.), Nicomachean Ethics (pp. 310-311). Princeton: Princeton University Press.

Blum, L. A. (1980). Friendship, altruism and morality. Boston: Routledge and Kegan Paul publishers.

Boatright, J. (2002). Contractors as stakeholders: Reconciling stakeholder theory with the nexus-of-contracts form. Journal of Banking and Finance, 26, 1837-1852.

Bowie, N. E. (1999). Business ethics: A Kantian analysis. Malden: Blackwell Publishers.

Buchanan, A. (1996). Perfecting imperfect duties: Collective action to create moral obligations. Business Ethics Quarterly, 6(1), 27-42.

Choi, S., \& Storr, V. H. (2016). Can trust, reciprocity, and friendship survive contact. In J. A. Baker \& M. D. White (Eds.), Economics and the virtues. Oxford: Oxford University Press.

Coase, R. H. (1937). The nature of the firm. Economica, 4, 386-405.

Cooper, J. M. (1980). Aristotle on friendship. In A. O. Rorty (Ed.), Essays on Aristotle's ethics. Berkeley: University of California Press.

Duffie, D. (1989). Futures markets. Englewood Cliffs: Prentice Hall.

Dworkin, R. (1977). Taking rights seriously. Cambridge: Harvard University Press.

Fackler, P. L. (1993). Delivery and manipulation in futures markets. Journal of Futures Markets. doi:10.1002/fut.399013069. 
Fama, E. F. (1980). Agency problems and the theory of the firm. Journal of Political Economy, 88(2), 288-307.

Gladwell, M. (2011). Creation Myth," Annals of Business, The New Yorker, Archive, May 16 (2011). http://Gladwell.com/Category/ The-New-Yorker-Archive/.

Hart, O. D. (1993). Incomplete contracts and the theory of the firm. In E. O. Williamson \& S. G. Winter (Eds.), The nature of the firm. New York: Oxford University Press.

Hill, T. E. (2012). Virtue, rules and justice. Oxford: Oxford University Press.

Hume, D. (1739). A treatise of human nature. Buffalo: Prometheus Books. (reprint 1992).

Jensen, M. C., \& Meckling, W. H. (1976). Theory of the firm: Managerial behavior, agency costs and ownership structure. Journal of Financial Economics, 3, 305-360.

Kant, I. (1784). Idea for a universal history with cosmopolitan intent. In A. W. Wood (Ed.), Basic Writings of Kant. New York: The Modern Library. (2001).

Kant, I. (1785). Fundamental principles of the metaphysics of morals. In A. W. Wood (Ed.), Basic writings of Kant., The modern library classics New York: The Modern Library.

Kant, I. (1793). Religion within the limits of reason alone. In A. W. Wood (Ed.), Basic writings of Kant., The modern library classics New York: The Modern Library.

Kant, I. (1797). In M. Gregor (Ed.), The metaphysics of morals. Cambridge: Cambridge University Press.

Korsgaard, C. M. (1986). The right to lie: Kant on dealing with evil. Philosophy and Public Affairs, 15, 583-599.

Korsgaard, C. M. (1996). Creating the kingdom of ends. Cambridge: Cambridge University Press.

Mansell, S. (2013). Shareholder theory and Kant's theory of beneficence. Journal of Business Ethics, 117(3), 583-599.

O'Neill, O. (1995). Constructions of reason: Explorations of Kant's practical philosophy. Cambridge: Cambridge University Press.

Ohreen, D. E., \& Petry, R. A. (2012). Imperfect duties and corporate philanthropy: A Kantian approach. Journal of Business Ethics, 106(3), 367-381.
Rawls, J. (1951). Outline of a decision procedure for ethics, Philosophical Review, 60(2): 177-197. Reprinted in Collected Papers-John Rawls, Edited by Samuel Freeman, Harvard University Press, 1999.

Robinson, R. (2016). Friendships of virtue, pursuit of the moral community, and the ends of business. Journal of Business Ethics. doi:10.1007/s100551-016-3277-5. (published online-Open Access, 8/03/2016)

Schneewind, J. B. (1992). Autonomy, obligation, and virtue: An overview of Kant's moral philosophy. In P. Guyer (Ed.), The Cambridge companion to Kant (pp. 309-341). Cambridge: Cambridge University Press.

Smith, J. (2012). Corporate duties of virtue: Making (Kantian) sense of corporate social responsibility. In D. Arnold \& J. Harris (Eds.), Kantian business ethics: Critical perspectives. Northampton: Edward Elgar Publishers.

Smith, C. W., \& Warner, J. B. (1979). On financial contracting: An analysis of bond covenants. Journal of Financial Economics, 7, $117-161$.

Sullivan, R. (1994, 1997). An Introduction to Kant's Ethics, Cambridge: Cambridge University Press.

Wang, H. C., He, J., \& Mahoney, J. T. (2009). Firm-specific knowledge resources and competitive advantage: The roles of economic and relationship-based employee governance mechanisms. Strategic Management Journal, 30, 1265-1285. doi:10. $1002 / \mathrm{smj} .787$.

White, M. D. (2011). Kantian ethics and economics. Stanford: Stanford University Press.

Williamson, O. E. (1985). The economic institutions of capitalism. London: The Free Press, Collier Macmillan Publishers.

Williamson, O. E., \& Winter, S. G. (1993). The nature of the firm: origins, evolution, and development. New York: Oxford University Press.

Xerox PARC. (2016). Wikipedia, http://en.wikipedia.org/wiki/ PARC_(company). 